\title{
Parents' Well Being and Child Care Time: The Case of Italy
}

\author{
Marina Zannella ${ }^{1}$ \\ ${ }^{1}$ Department of Methods and Models for the Economy, the Territory and Finance (MEMOTEF); "Sapienza" \\ University of Rome
}

\begin{abstract}
.
Time spent with children as well as the variety of activities performed has increased over the last decades. The spread of "intensive-parenting" social norms in recent years has been associated with positive effects of the wellbeing and healthy development of children. However, the effects of childcare giving on the wellbeing of parents are less clear. While a substantial body of literature has shown lower levels of subjective well-being among parents compared to childless people, only a limited number of studies based on the US have analysed the relation between childcare time and parents' wellbeing. In this study, we use micro data from the latest edition of the Italian Time Use Survey (2013-2014) to explore the relation between the use of time of parents for children and their subjective wellbeing, after having controlled for a number of individual and household characteristics. We take advantage of the detailed survey's information to distinguish between the different activities performed with children. Finally, we analyse different measures of parental satisfaction with childcare time, including survey's direct questions as well as information on momentary assessments of childcare activities based on time diary episode scores.
\end{abstract}

Keywords: Gender, Time Use, Well Being, Child Care 


\section{Introduction (TNR 14pt., bold)}

A large body of literature has documented a cultural shift towards more time-intensive and child-centered parenting (e.g. Craig et al. 2014). Those studies have also shown 'concerted cultivation', i.e. conspicuous and diversified parental time investment, to be positively associated to an healthy development of children (e.g. Laureau 2002). However, the implications of intensive parenting for the wellbeing of adults are less clear (Musick et al 2016). Parents have less free time available and are more likely to feel rushed than nonparents. There is a widespread recognition of mothers being more stressed than fathers. Skeptics may argue that this is merely an effect of reported data, but a recent study demononstated levels of biomarkers associated with chronicstress to be $18 \%$ higher among working mothers with one child while the figure rises to $40 \%$ for those with two children (Chung and van der Host 2018). However, studies on the effects of childcare on the wellbeing of parents led to different conclusions. For instance, in March 2012, The New York Times ran the headline "Do Women Like Child Care More than Men?"; the article, based on findings from a scientific study (Rhoads and Rhoads 2012), provided a positive answer to the question. The suggestion that women enjoy child caregiving more than men has been offered as a partial explanation for the slowdown in the gender revolution (e.g.

Coontz 2013). Differently, in their time use study of parental satisfaction with childcare time in US, Connelly and Kimmel (2014) found that both mothers and fathers enjoy their time spent in child caregiving but fathers even more so than mothers. Similarly, Musick and colleagues (2016), using microdata from the American Time Use Survey, found that parents consistently report greater subjective well-being in activities with children than without. Mothers, however, report less happiness, more stress, and greater fatigue in time with children than do fathers.

While a substantial body of work shows lower levels of subjective well-being among parents compared to childless people (e.g. Aassve et al. 2012; Myrskyla and Margolis 2014), fewer studies have analysed the relation between childcare time and parents' well-being. Most of these studies have been focusing on US, while little is know about European countries due to the more limited availability of time use surveys (TUS). Furthermore, information on wellbeing are less frequently collected in European TUS.

The main aim of this article is to explore the relation between objective measures of time devoted to childcare and subjective wellbeing. To this end, we use micro data from the latest edition of the Italian Time Use Survey (2013-2014). Existing literature has shown not only the quantity of parental time but also the typology of activities performed to differ across mothers and fathers with the former doing more routine work compared to the latter (e.g. Craig and Mullan 2011). We take advantage of the detailed time use information to distinguish among different typologies of childcare activities, i.e. physical care, playing, talking or teaching to the child. In addition to the daily diary, the survey also collects detailed information on individuals and households including socio-demographic information as well as information on different aspects related to wellbeing, satisfaction and happiness. Moreover, the survey reports 
information on background variables including the use of formal childcare, informal help from the family (e.g. grandparents) or the use of market services (colf, baby sitter). This typology of

data represents, thus, a precious source of information to study the existing relations between subjective wellbeing, time structures, individual characteristics and family composition.

\section{Data}

The study builds on micro-data from the Italian Time Use Survey for the year 2013/14. TUS includes three data files: the individual file, the daily diary and weekly diary ${ }^{1}$. The daily diary consists of time data collected through the diary technique: respondents record time use during the previous 24 hours in their own words. Time diaries are randomly distributed across the days of the week to all household members aged 3 years and over. ${ }^{2}$ Diaries provide extremely detailed information, including: description of the main activity carried out by the respondent, the possible presence of a parallel secondary activity, the location where the activity was performed and, if applicable, the presence of another person. The individual file collects information about the socio-demographic characteristics of the individual, the characteristics of the household, background information and information on the wellbeing of the respondents. Wellbeing information include questions on the subjective perception of wellbeing in specific domains (e.g. .....) as well as more general questions on life satisfaction and happiness. Specific information on parental satisfaction with time for children were asked. Furthermore, the survey contains detailed activity-specific information on the subjective perception of time use by asking how pleasant the moment was for each episode.

Our main objective is to analyse the interrelationships between the use of time of parents for childcare activities and their subjective wellbeing, after having controlled for a number of individual and household characteristics. To this end, we limit our analysis to parents of dependent children (aged up to 14 years), which provides us with a total sample size of 6,582 parents. We analyse the following wellbeing information related to childcare:

- Are you satisfied with the quantity of time spent with your child/children? Yes; No, it's too much; No, it's too little

- Are you satisfied with the couple's division of childcare time?

Unfortunately, there is no information on the perception of the quality of time spent with children. However, we take advantage of the episode scores to calculate the share of pleasant/unpleasant time spent in childcare activities. We, thus, analyse how the different information on parental satisfaction and wellbeing relate to individual, household and

\footnotetext{
${ }^{1}$ The analysis builds on data from the individuals and the daily diary files.

${ }^{2}$ Diaries for pre-school children are filled by their parents. Household members are supposed to fill in the diary within the same day.
} 
background characteristics. Nevertheless, parental perception of childcare time may at least partly depend by general levels of life satisfaction which we take into account in our analysis.

\section{Descriptive findings}

The majority of parents are satisfied with the quantity of time devoted to children $(56.7 \%)$. However, more than $40 \%$ of the respondent want to spend more time with their children, while less than $2 \%$ perceive that they spend too much time in childcare activities. About $67 \%$ of mothers are satisfied with their parental time, but the number drops to $44 \%$ when looking at fathers (Table 1). The share of unsatisfaction is higher among those with high education, which may partly depend by their higher time investment into career but also by the more widespread diffusion of intensive partenting social norms. Parents of two or more children are more likely to be unsatisfied than those with one child. Looking at the age of the youngest child in the family, the highest share of satisfaction is recorded among those with children aged less than two years which my be explained by the low diffusion of formal childcare for toddlers in Italy (and, thus, by the generally higher levels of time spent by parents with chidlren at this age).

Table 1: Parental satisfaction with quantity of time devoted to children

\begin{tabular}{lccc} 
& YES & $\begin{array}{c}\text { NO, IT'S TOO } \\
\text { MUCH }\end{array}$ & $\begin{array}{c}\text { NO, IT'S TOO } \\
\text { LITTLE }\end{array}$ \\
\hline GENDER & & 1.5 & 54.1 \\
Men & 44.4 & 2.2 & 30.7 \\
Women & 67.1 & & \\
AGE GROUP & & 1.1 & 31.9 \\
$25-34$ & 67.0 & 1.8 & 42.9 \\
$35-44$ & 55.3 & 2.5 & 45.8 \\
$45-54$ & 51.7 & & \\
HOUSEHOLD TYPE & & 1.8 & 41.6 \\
Couple & 56.6 & 2.2 & 40.2 \\
Single-parent & 57.6 & & 47.0 \\
EDUCATION & & 1.2 & 44.3 \\
High & 51.8 & 2.3 & 35.3 \\
Medium & 53.4 & 1.7 & \\
Low & 63.0 & & 52.6 \\
EMPLOYMENT & 46.0 & 1.3 & \\
Employed & & & \\
& & & \\
& & & \\
\end{tabular}


N. OF DEPENDENT CHILDREN

One

Two

Three and more

YOUNGEST CHILD

Less than three years

From three to five years

50.6

From six to ten years

GEOGRAPHIC AREA

North

Centre

South

MUNICIPALITIES TYPE

Metropolitan area

Up to 10,000 inhab.

More than 10,000 inhab.
56.8

\section{8}

53.2

61.2

2.6

39.7

44.2

45.4

35.7

3.2

59.3
45.5

41.7

2.1

1.5

38.7

\section{References}

[1] Chung, H., \& van der Horst, M. (2018). Flexible working and unpaid overtime in the UK: The role of gender, parental and occupational status. Social Indicators Research, 1-26.

[2] Connelly, R., \& Kimmel, J. (2015). If you're happy and you know it: How do mothers and fathers in the US really feel about caring for their children?. Feminist Economics, 21(1), 134Hill, R. M. (1997). The single-vendor single-buyer integrated production-inventory model with a generalized policy, European Journal of Operational Research, vol. 97, pp. 493-499.

[3] Coontz, S. (2013). Why Gender Equality Stalled?. New York Times, February 16

[4] Craig L., \& Mullan, K. (2011). How mothers and fathers share childcare: A cross-national time-use comparison. American Sociological Review, 76(6), 834-861.

[5] Lareau, A. (2002). Invisible inequality: Social class and childrearing in black families and white families. American Sociological Review, 67, 747-776. 
[6] Musick, K., Meier, A., \& Flood, S. (2016). How parents fare: Mothers' and fathers' subjective well-being in time with children. American Sociological Review, 81(5), 10691095.

[7] Rhoads, S. \& Rhoads, C. (2012). Gender Roles and Infant/Toddler Care: Male and Female Professors on the Tenure Track, Journal of Social, Evolutionary and Cultural Psychology 6(1), 13-31. 